\title{
EVALUASI HEURISTIK PADA WEB BASED LEARNING DALAM UPAYA MENINGKATKAN KEMUDAHAN PENGISIAN TRY OUT UJI KOMPETENSI BAGI MAHASISWA D3 RMIK STIKES YAYASAN RS Dr.SOETOMO
}

\author{
Amir Ali $^{*}$, Eka Wilda Faida* \\ *Dosen D3 STIKES Yayasan Rumah Sakit Dr.Soetomo \\ e-mail: ${ }^{1}$ amir.consulting@gmail.com, ${ }^{2}$ ekawildafaida@gmail.com
}

\begin{abstract}
ABSTRAK
Penelitian ini berisikan tentang evaluasi halaman antar muka dari aplikasi web based learning try out uji kompetensi rekam medik dan informasi kesehatan (RMIK). Tujuan dari penelitian ini adalah mengevaluasi secara heuristic halaman antarmuka dari aplikasi web based learning try out uji kompetensi RMIK. Evaluasi halaman antar mukanya menggunakan metode evaluasi heuristik. Evaluasi terhadap halaman antar muka dengan metode evaluasi heuristik ini dimulai dari melakukan pengamatan terhadap aplikasi web based learning try out uji kompetensi RMIK yang dilakukan oleh 79 pengguna kemudian melakukan usability testing yaitu melakukan sejumlah tugas terstruktur termasuk melakukan ujian try out uji kompetensi serta mengisi kuesioner yang mewakili 10 prinsip evaluasi heuristik. Berdasarkan hasil penelitian didapatkan nilai rata-rata (mean) sebesar 2.91 untuk perhitungan dengan menggunakan skala likert yang masuk pada kategori mudah dalam hal penggunaan aplikasinya. uji reabilitas dan validitas instrument penelitian diperoleh nilai cronbach alfa sebesar 0,907 .
\end{abstract}

Kata Kunci : Evaluasi Heuristik, Usability Testing, Usability

\begin{abstract}
This study contains the evaluation page of the web application interface based learning try out competition exam. Evaluation of user interface using heuristic evaluation method. Stages evaluation of the user interface by using heuristic evaluation method that starts from the observation made by 79 respondents then perform usability testing as well as fill out questionnaires representing 10 principles of heuristic evaluation. Based on the results, the average value of 2.91 for the calculation by using a Likert scale. This value belongs to the category of easily used. That is to say the application is easy to use. test reliability and validity of research instrument obtained a Cronbach alpha value of 0,907.
\end{abstract}

Kata Kunci : Evaluasi Heuristik, Usability Testing, Usability 


\section{PENDAHULUAN}

Pembelajaran bisa dilakukan dengan menggunakan teknologi. Salah satunya menggunakan teknologi web based learning sebagai media pembelajaran bagi mahasiswa. Diharapkan setelah melakukan pembelajaran menggunakan teknologi ini akan memudahkan mahasiswa untuk mengevaluasi hasil belajarnya terutama bagi dosen pengampu mata kuliah agar mengetahui sejauh mana mahasiswanya paham akan mata kuliah yang diajarkan. Walaupun sangat besar manfaatnya, web pembelajaran sangat kecil sekali untuk dikritisi dari aspek usability. Konsep usability perlu diterapkan pada halaman antarmuka aplikasi. Dalam pengembangan aplikasi perangkat lunak komputer, halaman antarmuka dari perangkat lunak adalah bagian yang amat penting. Pengguna sering menilai mutu dari sistem hanya dengan melihat antarmuka dari sistem tersebut. Oleh karena itu diperlukan pendekatan menggunakan evaluasi terhadap web based learning dari sisi usability system, agar user mudah untuk mengerti dan paham penggunaanya sehingga dapat membantu user dalam proses belajar. Salah satu pendekatan itu menggunakan evaluasi heuristik yang dikemukakan oleh Jacob Nielsen dan Mack. Pada penelitian ini evaluasi terhadap web based learning yang akan diteliti menggunakan metode evaluasi heuristic yang dikemukakan oleh Jacob Nielsen dan Mack dengan 10 aturan heuristik. Tujuan pada penelitian ini adalah mengevaluasi aplikasi web based learning secara heuristik menggunakan 10 faktor aturan heuristik yang dikemukakan oleh Jacob Nielsen dan Mack.

\section{Metode}

Jenis penelitian ini adalah penelitian deskriptif kuantitatif, yaitu suatu metode penelitian yang dilakukan dengan tujuan utama untuk membuat gambaran atau deskripsi tentang suatu keadaan
Dapat kami jelaskan desain penelitian ini sebagai berikut

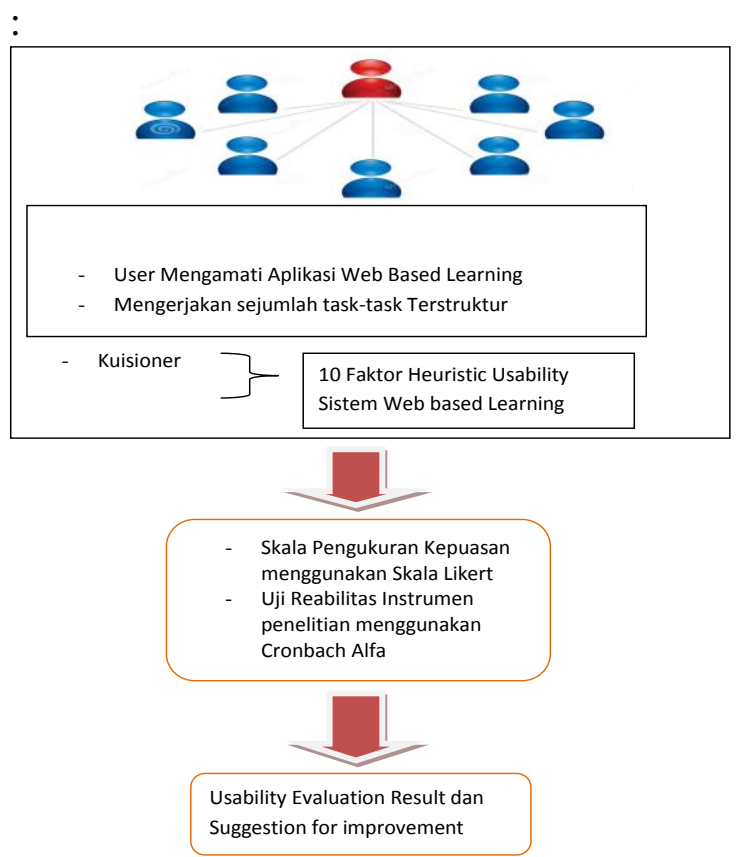

\section{Teknik Sampling}

Dalam penelitian ini, digunakan teknik sampling non probability sampling dimana pengambilan sampel didasarkan dengan kriteria tertentu. Metode yang digunakan dalam teknik sampling non probability sampling ini yaitu accidental sampling. Pengambilan sampel ini didasarkan pada kenyataan bahwa responden kebetulan muncul

\section{Sampel dan Karakteristiknya}

Penelitian ini menggunakan sampel mahasiswa semester 6 D3 RMIK yang berjumlah 79 orang. Dengan karakteristik mahasiswa tingkat akhir yang telah mengerti dan mempelajari mata kuliah yang akan di try out kan pada aplikasi web based learning try out uji kompetensi RMIK.

\section{Waktu dan Tempat Penelitian}

Penelitian ini dilaksanakan pada bulan Maret-Juni 2016 di Stikes Yayasan Rumah Sakit Dr.Soetomo Surabaya.

\section{Instrumen yang digunakan}

Instrumen yang digunakan berupa questioner yang berisikan 10 kriteria faktor evaluasi heuristic pada aplikasi web based learning try out uji kompetensi D3 RMIK. 10 kriteria tersebut adalah tampilan 
informasi dari status sistem, komunikasi dengan pengguna, kontrol menu dari sistem, konsistensi dan standar, pencegahan error, kemampuan untuk mengingat, fleksibel dan efisien dalam penggunaannya, estetika dan minimalis desain, membantu pengguna dalam mengakui, mendiagnosa dan memulihkan sistem dari kesalahan,dan bantuan dan dokumentasi.

\section{Uji Analisis Statistik}

Dalam penelitian ini, akan dilakukan pengujian reabilitas instrument penelitian dengan menggunakan cronbach alfa. Uji reabilitas dan validitas lebih menitikberatkan kepada instrumen penelitian yang berupa kuesioner. Rumus untuk menghitung koefisien reliabilitas instrumen dengan menggunakan cronbach alpha adalah sebagai berikut:

$\mathrm{r}=$ koefisien reliabilitas instrumen (cronbach alfa)

$\mathrm{k}=$ banyaknya butir pertanyaan atau banyaknya soal

$\sum \sigma_{\mathrm{b}}{ }^{2}=$ total varians butir

$\sigma_{\mathrm{t}}^{2}=$ total varian

Rumus ini jika diimplementasikan dengan menggunakan aplikasi SPSS 17 maka untuk menghitung nilai cronbach alfa dapat menggunakan menu analyze sub menu scale untuk submenu reability analysis.

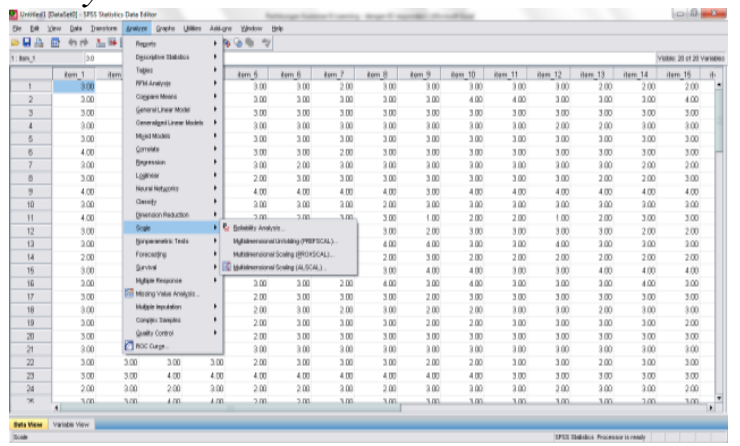

Gb 2. Form Menu Uji Cronbach Alfa
Sebelum menghitung nilai cronbach alfa, maka perlu menginputkan variabel apa saja yang digunakan pada penelitian..

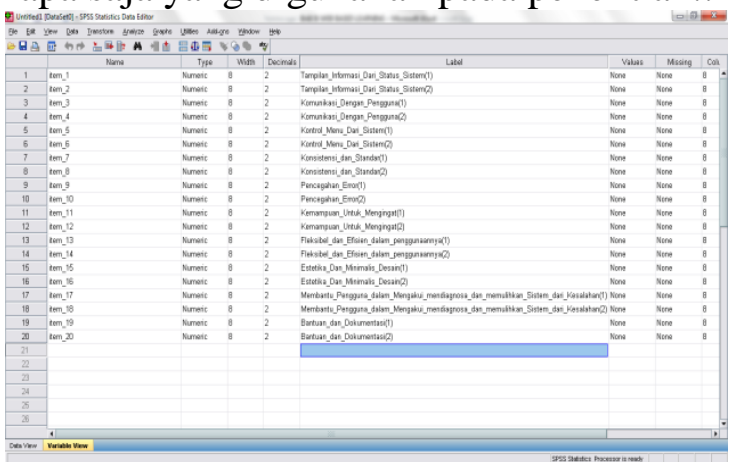

Gb 3. Input Data Variabel Penelitian Setelah variabel penelitian diinputkan maka, hasil jawaban 20 pertanyaan untuk 79 responden terhadap penilaian halaman antarmuka dari web based learning yang dinyatakan dalam skala 1-4 dimasukkan pada kolom yang telah dipersiapakan.

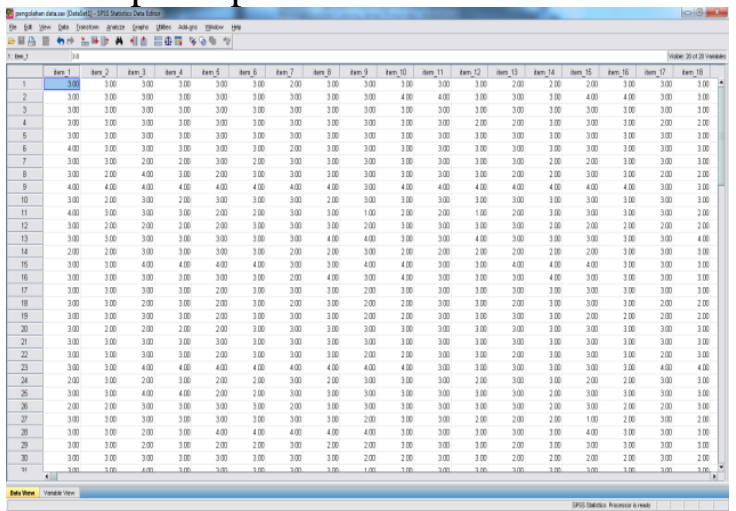

Gb 4. Hasil Jawaban Kuesioner

Untuk keperluan pengukuran kepuasan penggunaan aplikasi web based learning menggunakan skala likert pada SPSS dengan dengan menggunakan menu tranform sub menu compute variable.

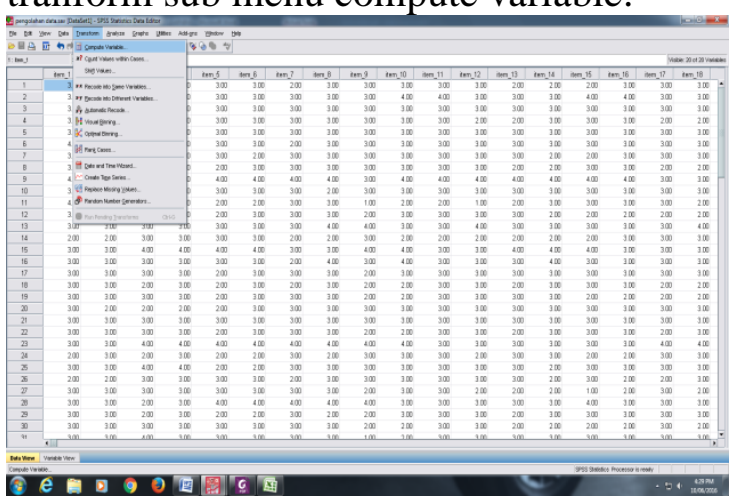

Gb 5. Menu Transform Compute Variabel 
Dimana proses perhitungannya dengan menjumlahkan hasil jawaban kuesioner dari 20 pertanyaan untuk tiap responden yang berjumlah 79 orang dan melakukan pengkategorian berdasarkan skala interpretasi interval serta melakukan analisis deskriptif dengan menggunakan menu Analyze sub menu Descriptive statistics frequencies Analisa deskriptif ini digunakan untuk melihat gambaran kemudahan penggunaan aplikasi web based learning tryout uji kompetensi D3 RMIK yang masuk pada kategori yang mana berdasarkan skala interprestasi interval yang telah dibuat.

\section{HASIL DAN PEMBAHASAN}

Berdasarkan tujuan penelitian yang ingin dicari yaitu

1.Mengidentifikasi user interface aplikasi web based learning dengan 10 kriteria evaluasi. 10 kriteria tersebut yaitu :

a. Tampilan informasi dari status sistem. Prinsip ini berkaitan langsung dengan beberapa pertanyaan seperti:"Dimana saya sekarang?","Dimana jalan selanjutnya?". Berdasarkan keterangan tersebut, jika kita memperhatikan gambar 6 dibawah ini :

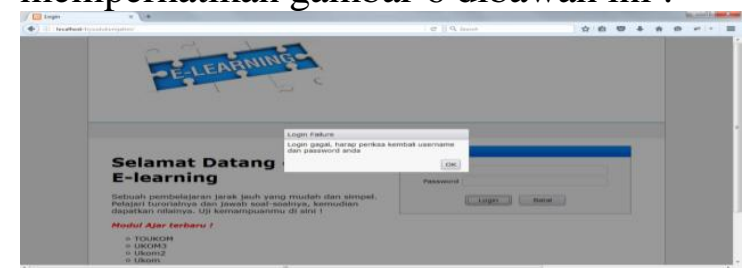

Gb 6. feedback berupa pesan kesalahan data username dan passowd

seandainya user salah dalam memasukkan username dan password, sistem akan memberikan feedback berupa pesan kesalahan data username dan passowd. Berdasarkan feedback itu, pengguna tahu apa yang harus dilakukan.

b. Komunikasi dengan pengguna

Sistem dapat berkomunikasi dengan pengguna dengan bahasa yang dimengerti oleh pengguna, dapat melalui istilah, frase, Symbol, dan konsep yang familier dengan pengguna. Berdasarkan informasi diatas, maka jika kita perhatikan gambar 7 dibawah ini :

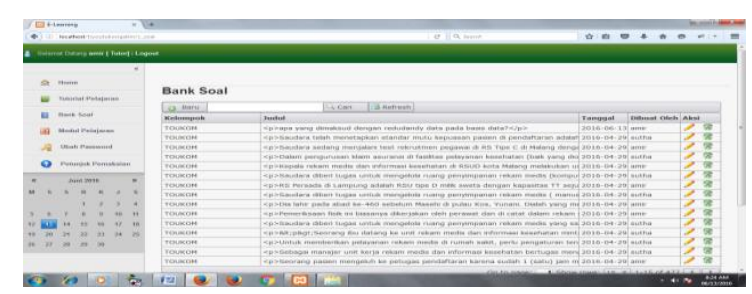

Gb 7. Penggunaan istilah pada form bank soal

terdapat istilah seperti tutorial pelajaran, bank soal, modul pelajaran, ubah password, dan petunjuk pemakaian, dimana istilah ini mudah dipahami oleh pengguna.

c. Kontrol menu dari sistem

Sistem menyediakan kontrol menu aplikasi yang mudah. Berdasarkan informasi diatas maka jika perhatikan pada gambar 8,maka control menu aplikasi telah tersedia pada aplikasi ini. Hal ini ditunjukkan jika pengguna ingin melihat kumpulan bank soal yang jumlahnya banyak, dapat kita navigasikan lewat tombol panah kanan dan panah kiri yang terdapat di bawah list form masing-masing halaman/page.

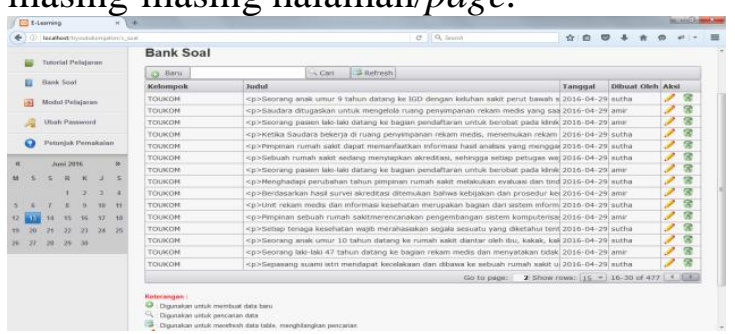

Gb 8. Menu Navigasi antar halaman pada bank soal

d. Konsistensi dan standar

Evaluasi konsistensi dan standar dimaksudkan agar suatu sistem menjadi standard, konsisten dalam hal penulisan kalimat, jenis huruf dan lain sebagainya. aplikasi pada web based learning try out uji kompetensi D3 RMIK memiliki konsistensi yang baik, dimana setiap halaman memiliki desain, warna, dan tema yang sama. Header dan fasilitas logout juga selalu berada di lokasi yang sama. Begitu juga dengan penulisan kalimat, huruf juga menggunakan kalimat dan huruf yang sama untuk tiap halaman dari aplikasi web based learning try out uji kompetensi D3 RMIK.

\section{e. Pencegahan error}


Evaluasi ini hampir serupa dengan evaluasi navigation. Tetapi yang lebih diutamakan adalah pencegahan pengguna ketika melakukan kesalahan, juga disediakan opsi konfirmasi sebelum pengguna melanjutkan aksinya

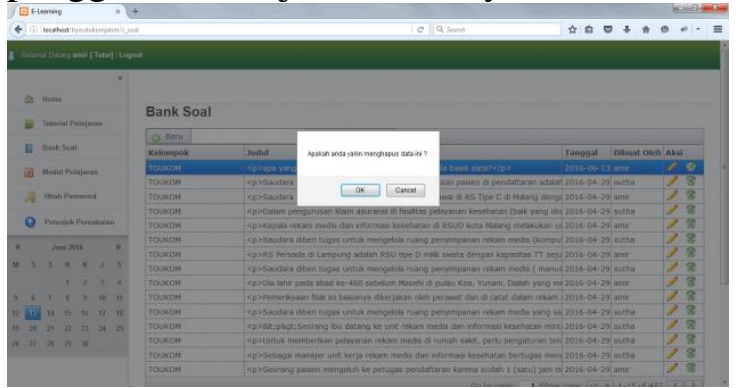

$\mathrm{Gb}$ 9. Pesan konfirmasi sistem sebelum menghapus data

Seperti pada gambar 9 diatas, sistem akan menampilkan pesan konfirmasi kepada userl pengguna jika data akan benar-benar dihapus. Sistem pada aplikasi web based learning ini telah dilengkapi fasilitas diatas yang berguna untuk opsi konfirmasi untuk melanjutkan aksinya terutama dalam menghapus data.

f. Kemampuan untuk mengingat

Simbol, aksi dan pilihan sistem harus terlihat oleh pengguna dan mudah untuk diakses. Sehingga pengguna tidak harus mengingat kembali informasi dimana harus memanggil object/icon, action dan option sistem ketika akan menggunakannya.

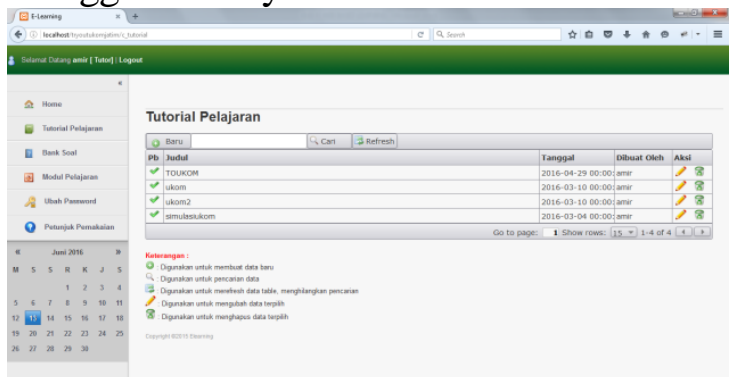

Gb 10. Penggunaan Icon, Action Sistem Seperti terlihat pada gambar 10 diatas, gambar sampah, pensil, gambar buku yang merupakan representasi dari icon, symbol yang dapat diingat dan mudah untuk diakses.

g. Fleksibel dan efisien dalam penggunaannya

Sistem harus dapat dibuat flexibel dan seefisien mungkin baik untuk digunakan pengguna yang expert maupun pengguna baru/ pemula. Penggunaan gambar/icon yang disimbolkan dengan gambar sampah dimana mengandung arti membuang, contohnya pada penghapusan data dapat kita gunakan gambar/icon sampah ini.

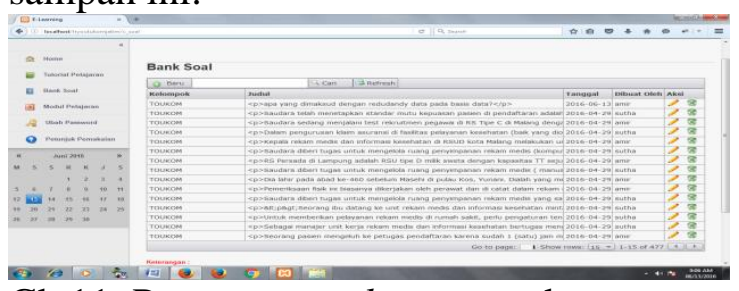

Gb 11. Penggunaan shortcut pada halaman bank soal

h. Estetika dan minimalis desain

Sistem dialog dibuat secara aesthetic dan minimalis design. Juga harus mengandung informasi yang relevan dengan tugas/ kebutuhan yang diharapkan oleh pengguna.

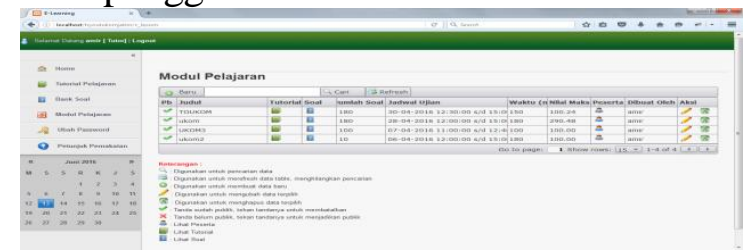

Gb 12. Form Modul yang terlihat Aesthetic dan minimalis design

i. Membantu pengguna dalam mengakui, mendiagnosa dan memulihkan sistem dari kesalahan

Sistem harus dapat memberikan pesan kesalahan/ error message dalam bahasa sederhana. Pesan kesalahan itu memberikan penjelasan kenapa hal tersebut terjadi dan bagaimana solusi seharusnya. Seperti terlihat pada gambar dibawah ini :

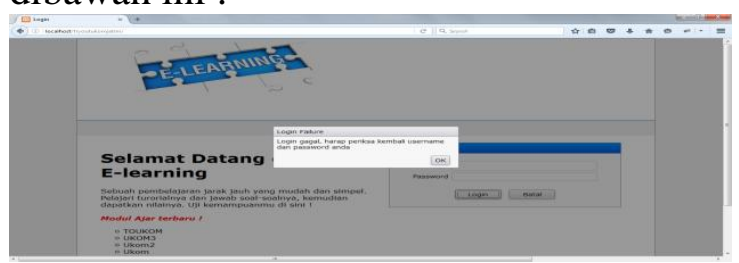

Gb 13. Informasi kesalahan user saat input username dan password j.Bantuan dan dokumentasi

Sistem harus disertai dengan informasi penggunaan dan documentasi lain yang berhubungan dengan sistem. 


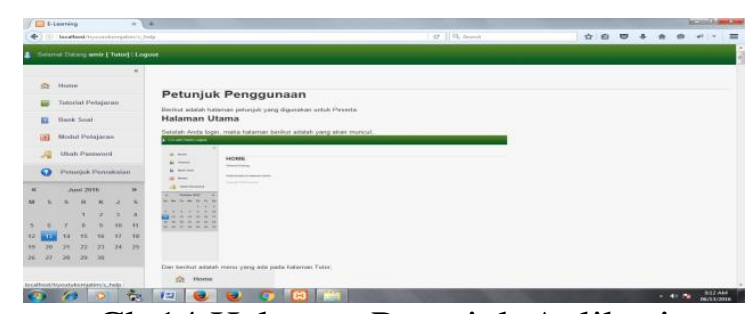

Gb 14.Halaman Petunjuk Aplikasi

2.Melakukan uji reabilitas instrumen penelitian menggunakan metode cronbach alfa.

Berdasarkan hasil pengujian instrumen penelitian menggunakan cronbach alfa didapatkan hasil didapat nilai Cronbach's Alpha 0,907 dengan Responden berjumlah 79 orang. Hal ini dapat dikatakan bahwa instrument penelitian dapat dikatakan valid dan reliabel merujuk pada table distribusi $r$ table signifikasi 5\% dimana nilainya > 0,221 untuk Responden berjumlah 79 orang

3.Melakukan pengukuran kepuasan penggunaan aplikasi web based learning dengan menggunakan skala likert.

Setelah menghitung total nilai jawaban responden dan melakukan pengkategorian berdasarkan skala interpretasi interval serta melakukan analisis deskriptif maka didapatkan hasil seperti gambar dibawah ini :

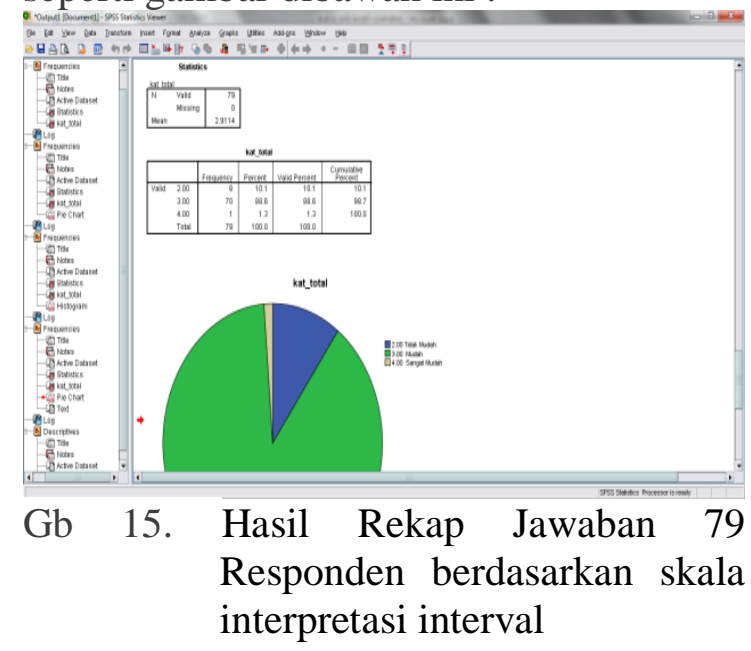

\section{DAFTAR PUSTAKA}

Arikunto, Suharsimi. 2005 . Manajemen Penelitian. Edisi Revisi. Jakarta : Rineka Cipta

Badre, Albert N. 2002. Shaping web
Berdasarkan keterangan diatas, maka didapatkan nilai rata-rata (mean) sebesar 2.91 dimana hal ini menginformasikan bahwasannya hal ini masuk pada kategori mudah.

\section{KESIMPULAN DAN SARAN}

Dari hasil penelitian, maka dapat kami simpulkan sebagai berikut :

1. Uji instrumen penelitian yang berupa kuesioner dengan 20 pertanyaan menggunakan cronbach alfa didapatkan nilai 0,907 untuk 79 responden. Sehingga instrumen penelitian ini dapat dikatakan valid dan reliable berdasarkan tabel distribuisi $\mathrm{r}$ table signifikasi 5\% dimana nilainya $>0,221$

2. Hasil perhitungan kepuasan penggunaan aplikasi web based learning Try Out Uji Kompetensi D3 RMIK dengan menggunakan skala likert diperoleh nilai rata-rata (mean) skornya $=2,91$. Dimana nilai ini masuk pada kategori mudah berdasarkan tabel kriteria interpretasi skor berdasarkan intervalnya.

Untuk saran ke depannya, kami menyarankan :

1. Agar penggunaan aplikasi web based learning dapat digunakan secara optimal maka 10 prinsip aturan heuristik dari Jacob Nielsen dan Mack perlu diterapkan.

2. Agar peneliti memperhatikan salah satu prinsip evaluasi heuristik yaitu help dan documentation yang perlu disertakan pada aplikasi agar penggunaan aplikasinya dapat digunakan dengan mudah oleh pengguna.

usability. United States, AddisonWesley Professional

Ghozali, Imam. 2002. Aplikasi analisis multivariant dengan program SPSS. Semarang : Badan Penerbit Universitas Diponegoro 
Jakob Nielsen.1992. Finding usability problems through heuristic evaluation. Bellcore 445 South Street Morristown, NJ 07962-1910

Loan I. Andone ,Napoleon Alexandru .2008. Heuristic evaluation of web based intelligent Tutoring System. The $4^{\text {th }}$ International Scientific Conference eLearning And software for education. Bucharest

Nanjiani, A Nader. Kelly, M Tom. 2004. E-Learning Goes Global: How the Cisco Networking Academy Transform Lives. Indianapolis, Pearson Education Cisco Press.

Nielsen, Jacob. 1994. Usability inspection method. New York. Jhon Wiley and Sons

Riduwan, Akdon. 2007. Rumus dan Data dalam Analisis Statistika. Bandung : Penerbit Alfabeta

Sastramihardja dkk. 2008. Pengukuran Usability Dengan Sarana task model dalam user center software development.

Wingnjosoebroto dkk. 2009. Perancangan Interface Prototype Web Berdasarkan Pada Aspek Usability.

Sukestiyarno. 2014. Statistika Dasar. Yogyakarta : Andi Offset. 